\title{
A rationale for tRNA modification circuits in the anticodon loop
}

\author{
LU HAN and ERIC M. PHIZICKY \\ Department of Biochemistry and Biophysics, Center for RNA Biology, University of Rochester School of Medicine, Rochester, \\ New York 14642, USA
}

\begin{abstract}
The numerous post-transcriptional modifications of tRNA play a crucial role in tRNA function. While most modifications are introduced to tRNA independently, several sets of modifications are found to be interconnected such that the presence of one set of modifications drives the formation of another modification. The vast majority of these modification circuits are found in the anticodon loop (ACL) region where the largest variety and highest density of modifications occur compared to the other parts of the tRNA and where there is relatively limited sequence and structural information. We speculate here that the modification circuits in the ACL region arise to enhance enzyme modification specificity by direct or indirect use of the first modification in the circuit as an additional recognition element for the second modification. We also describe the five well-studied modification circuits in the $A C L$, and outline possible mechanisms by which they may act. The prevalence of these modification circuits in the $A C L$ and the phylogenetic conservation of some of them suggest that a number of other modification circuits will be found in this region in different organisms.
\end{abstract}

Keywords: 3-methylcytidine; wybutosine; 5-methylcytidine; 2'-O-methylguanosine

tRNAs are heavily post-transcriptionally modified, and are modified at different stages of tRNA biogenesis (Nishikura and De Robertis 1981; Jiang et al. 1997; Phizicky and Hopper 2010; Ohira and Suzuki 2011), and these modifications are important for tRNA function in translation. While most modifications are introduced to tRNA independently, several modification circuits have been identified in which one or more modifications stimulates formation of a subsequent modification. All of the well-studied examples of this ordered modification occur in the anticodon loop ( $A C L$ ) region of the tRNA, but it is not known why ordered modification occurs, or why it is seemingly more prevalent in the $A C L$ region. Here we propose that this propensity for ordered modification evolved in the ACL region because of the requirement for specificity of these modifications, combined with the relative lack of distinctive information in the $A C L$ region.

Of the numerous tRNA modifications found in different organisms, the largest variety of modifications and the highest modification density occurs in the ACL region. For example, of the 25 chemically distinct modifications found in cytoplasmic tRNAs in the yeast Saccharomyces

Corresponding author: eric_phizicky@urmc.rochester.edu

Article is online at http://www.rnajournal.org/cgi/doi/10.1261/rna. 067736.118. cerevisiae, 15 are found in the 9 nucleotides (nt) of the $A C L$ region, comprising loop residues $N_{32}-N_{38}$ and the closing base pair $\mathrm{N}_{31}-\mathrm{N}_{39}$, while 16 are found in the remaining 67 or more nucleotides in the main body of the tRNA, comprising the acceptor stem, D-stem-loop, the bulk of the anticodon stem (from pairs $\mathrm{N}_{27}-\mathrm{N}_{43}$ to $\mathrm{N}_{30}-\mathrm{N}_{40}$ ), the T-stem-loop, and the variable arm (Fig. $1 A, B)$. Six of these modifications are found in both regions. A similar biased distribution of tRNA modifications is widely found in other organisms: Of the 28 distinct tRNA modifications in Escherichia coli, 21 are found in the ACL region, while eight are found in the main body; and of the 28 distinct modifications in cytoplasmic tRNAs in humans, 17 are in the $A C L$ region and 17 are in the main body (Machnicka et al. 2014). Overall modification density is also heavily biased toward the ACL region in all organisms. Thus, among sequenced eukaryotic cytoplasmic tRNAs, on average $30 \%$ of the ACL region residues are modified, while only $14.8 \%$ of the residues in the main body are modified (29.8\% and $14.7 \%$ in yeast), and these percentages

(C) 2018 Han and Phizicky This article is distributed exclusively by the RNA Society for the first 12 months after the full-issue publication date (see http://rnajournal.cshlp.org/site/misc/terms.xhtml). After 12 months, it is available under a Creative Commons License (Attribution-NonCommercial 4.0 International), as described at http://creativecommons.org/licenses/by-nc/4.0/. 
A

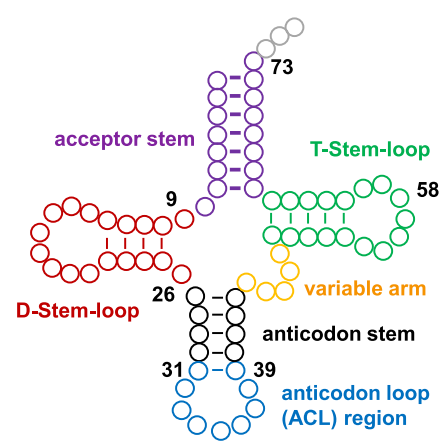

B

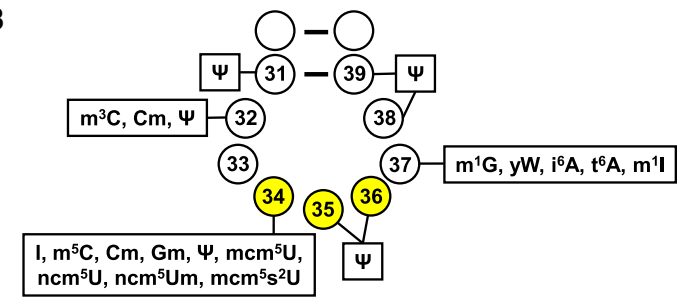

FIGURE 1. Schematic of tRNA and the biochemically distinct modifications found in the $S$. cerevisiae $A C L$ region. (A) The secondary structure of tRNA. Each circle represents a residue and is color-coded based on subdomains as indicated. (B) Schematic of modifications found in each residue of the $S$. cerevisiae $A C L$ region.

are similarly skewed in bacteria $(15.0 \%$ in the $A C L$ region and $5.7 \%$ in the main body) and in archaea (12.8\% and $9.6 \%$, respectively) (Machnicka et al. 2014).

The enrichment of the variety and density of modifications in the $A C L$ region is consistent with their important and varied roles during translation (Phizicky and Hopper 2010; Gu et al. 2014; Grosjean and Westhof 2016). A number of $A C L$ region modifications affect mRNA decoding or reading frame maintenance, by modulating codon:anticodon interactions and fine-tuning local structure during translation (Björk et al. 1989, 2007; Urbonavicius et al. 2001; Lecointe et al. 2002; Murphy and Ramakrishnan 2004; Waas et al. 2007; Weixlbaumer et al. 2007; Johansson et al. 2008; El Yacoubi et al. 2011; Maehigashi et al. 2014; Lorenz et al. 2017). Specifically, to ensure the efficiency and accuracy of translation, all tRNAs adopt a canonical U-turn structure in the $A C L$ to promote a stable codon-anticodon interaction in the ribosome A-site (Auffinger and Westhof 2001), and many ACL region modifications reinforce formation of this conserved loop structure by preventing base-pairing between nucleotides in the $A C L$, and by improving stacking interactions with neighboring residues (Murphy et al. 2004; Agris 2008). In addition, some $A C L$ region modifications have a crucial role in ensuring charging fidelity by serving as charging determinants or anti-determinants (Muramatsu et al. 1988; Pütz et al. 1994). The importance of ACL modifications relative to body modifications is underscored by their preferential phylogenetic retention. For example, in the human unicellular endosymbiont Candidatus Riesia pediculicola, which has a streamlined genome and likely a minimal tRNA modification set, the ACL modifications have been retained, whereas the body modifications have been lost (de Crécy-Lagard et al. 2012).

\section{Many modification enzymes target a single base at specific positions}

Most tRNA modification enzymes that modify body residues in the tRNA target a specific base, albeit by different mechanisms. For example, the yeast tRNA pseudouridine $(\Psi)$ synthase Pus 4 modifies $U_{55}$ by recognizing the identity of all the universally conserved nucleotides in the T-loop and its proximal stem as well as the structure of a portion of the T-arm (Becker et al. 1997), and consistently modifies mRNAs with a similar stem-loop motif (Lovejoy et al. 2014). Similarly, the yeast tRNA 5-methyluridine $\left(m^{5} U\right)$ methyltransferase modifies $U_{54}$ by recognizing several conserved nucleotides in the T stem-loop as well as the stacked T-stem and acceptor stem (Becker et al. 1997); the yeast 7-methylguanosine $\left(\mathrm{m}^{7} \mathrm{G}\right)$ tRNA methyltransferase Trm8/Trm82 recognizes the local structure around the variable loop and especially the $D$ arm and $T$ arm to modify residue $\mathrm{G}_{46}$ in the third residue of variable loops of $5 \mathrm{nt}$ (Leulliot et al. 2008), similar to the Aquifex aeolicus $\mathrm{m}^{7} \mathrm{G}$ MTase (Okamoto et al. 2004); and the E. coli $U_{20}$ dihydrouridine synthase DusC interacts with the $D$ and T stemloops to orient tRNA and $U_{20}$ near its catalytic site (Byrne et al. 2015). However, for some body modifications, the specificity of the enzymes is less clear. For example, the yeast 1-methylguanosine $\left(\mathrm{m}^{1} \mathrm{G}\right)$ methyltransferase $\operatorname{Trm} 10$ modifies 13 of 19 tRNA species that have a $G_{9}$ residue, with no obvious common sequence element, although Trm10 substrate recognition seems to depend on an as yet undefined structural conformation, since tRNAs with an extended variable loop are consistently unmodified (Swinehart et al. 2013). Similar arguments may explain the specificity of Trm3 for 2'-O-methylation of $\mathrm{G}_{18}$ on a subset of yeast tRNAs (Cavaillé et al. 1999), and of archaeosine tRNA-guanine transglycosylase, which modifies $\mathrm{G}_{15}$ on a subset of tRNAs through an alternative $\lambda$-form tRNA conformation (Ishitani et al. 2003).

In the $\mathrm{ACL}$ region, some modification enzymes also only require the presence of the correct nucleotide at the residue to be modified. One such example is yeast Tad2/3, which in the context of tRNA catalyzes inosine (I) formation in all eight sequenced tRNA with $A_{34}$ (Gerber and Keller 1999). Similarly, E. coli TruA recognizes and pseudouridylates $U_{38}, U_{39}$, and $U_{40}$ of the anticodon stem-loop, using the elbow and the D-stem of the tRNA to establish the orientation of tRNA and position the modification sites near the catalytic center (Hur and Stroud 2007), and its family member yeast Pus3 appears to modify all tRNAs with $U_{38}$ or $U_{39}$ (Machnicka et al. 2014). Slightly different recognition mechanisms involving relatively simple rules 
are used by some other $\mathrm{ACL}$ region enzymes. For example, enzymes responsible for $t^{6} A_{37}$ ( $\mathrm{N}^{6}$-threonylcarbamoyl adenosine) specifically recognize tRNAs with $U_{36}$ residues in all domains of life (Deutsch et al. 2012; Miyauchi et al. 2013). Another possible example in this category is the tRNA $i^{6} \mathrm{~A}_{37}$ ( $\mathrm{N}^{6}$-isopentenyladenosine) synthase, which requires $A_{36}-A_{37}-A_{38}$ and likely some other secondary elements (Persson et al. 1994; Motorin et al. 1997).

Consistent with their lack of discrimination among different tRNA species, many modifications are usually made independently of other modifications, since deletion of one modifying enzyme often does not alter levels of other modifications in the cell (Huang et al. 2005; Wilkinson et al. 2007; Kotelawala et al. 2008; Guy et al. 2012; Han et al. 2015).

\section{Some modification enzymes require prior modifications at other residues for efficient modification}

In contrast to tRNA body residues, some residues in the $A C L$ differ greatly in their modifications in different tRNAs. Thus, $U_{34}$ has five different fates in different yeast tRNAs: It can be unmodified, or it is modified to one of four different derivatives (Fig. 1B). Similarly, $C_{32}$ is unmodified or modified to either of two different derivatives in different tRNAs; $A_{37}$ is unmodified or modified to three different derivatives; and $\mathrm{G}_{37}$ is modified to either of two derivatives.

This variability of modification of different $A C L$ residues in different tRNAs requires unique mechanisms of recognition. As we document further below, a subset of these mechanisms involves prior modification of other residues (Fig. 2). Recent examples of such modification circuits include wybutosine (yW) formation at $\mathrm{m}^{1} \mathrm{G}_{37}$ of tRNA ${ }^{\text {Phe }}$ in Schizosaccharomyces pombe, $S$. cerevisiae and humans, which is greatly stimulated by 2'-Omethylated $\mathrm{C}_{32}(\mathrm{Cm})$ and $\mathrm{G}_{34}(\mathrm{Gm})$ (Guy and Phizicky 2015; Guy et al. 2012, 2015); 3-methycytidine $\left(\mathrm{m}^{3} \mathrm{C}\right)$ at $\mathrm{C}_{32}$, which is greatly stimulated by prior $i^{6} \mathrm{~A}_{37}$ formation in $S$. pombe, $S$. cerevisiae, and likely mouse (Arimbasseri et al. 2016; Han et al. 2017), or by prior $t^{6} A_{37}$ (Han et al. 2017); $\mathrm{Cm}_{34}$ or $\mathrm{Um}_{34}$ modification of E.coli tRNA ${ }^{\text {Leu(CAA) }}$ and tRNA ${ }^{\text {Leu(UAA), }}$ which is stimulated by $i^{6} A_{37} ; 5$-methycytidine $\left(\mathrm{m}^{5} \mathrm{C}\right)$ at $\mathrm{C}_{38}$ in $\mathrm{S}$. pombe and Dictyostelium discoideum, which is stimulated by prior queuosine $(\mathrm{Q})$ formation at residue 34 (Muller et al. 2015); and $A$ to I editing at $N_{34}$ of
Trypanosoma brucei tRNA ${ }^{\text {Thr(AGU) }}$, which is stimulated by prior $\mathrm{m}^{3} \mathrm{C}_{32}$ formation and then deamination to form $\mathrm{m}^{3} \mathrm{U}$ (Rubio et al. 2006, 2017). Note that some other complex modifications require a multistep reaction, and the dependence of a latter step reaction on the prior modification intermediates at the same residue (Grosjean et al. 1995; Morl et al. 1995) is not considered as a modification circuit by this review, and will not be further discussed.

Although a few modification circuits are reported to occur in the tRNA main body, all of them are found in Thermus thermophilus, an extreme thermophilic eubacteria of which tRNAs are adapted to high growth temperatures (Yokoyama et al. 1987). Examples include formation of 2-thioribothymidine $\left(\mathrm{s}^{2} \mathrm{~T}\right)$ from ribothymidine $(\mathrm{rT})$ at $U_{54}$, which is stimulated by 1 -methyladenosine $\left(m^{1} A\right)$ at $A_{58}$ (Shigi et al. 2006); $G_{18}$ and $m^{1} G_{37}$, which are stimulated by $\mathrm{m}^{7} \mathrm{G}_{46}$ at higher culture temperatures (Tomikawa et al. 2010); and 5-methyl-2-thiouridine $\left(\mathrm{m}^{5} \mathrm{~s}^{2} \mathrm{U}\right)$ at $\mathrm{U}_{54}$ and $\mathrm{m}^{1} A_{58}$, which are negatively regulated by $\Psi_{55}$ at lower culture temperatures (Ishida et al. 2011). The latter two circuits are thought to be part of a network that maintains the proper balance of tRNA modifications and responds to temperature changes (Ishida et al. 2011).

\section{A hypothesis to explain the prevalence of $A C L$ region modification circuits}

It is intriguing to consider why these modification circuits tend to occur in the ACL region, but not in other parts of a tRNA. One possible explanation is that $\mathrm{ACL}$ region modifications introduced first may act as additional recognition elements for other modifications in response to the requirement for modifications with great variation and high density
A

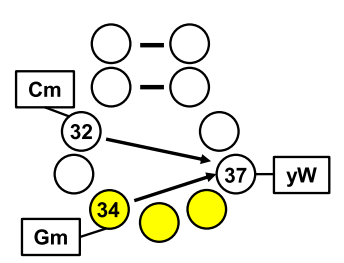

B

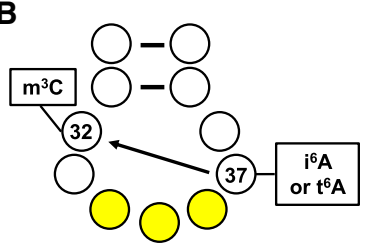

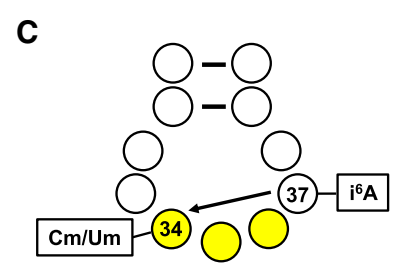

D

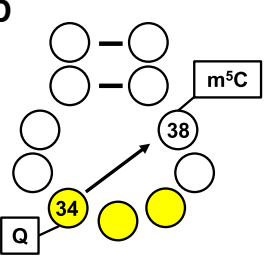

E

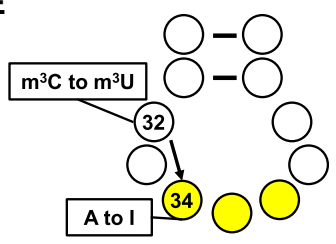

FIGURE 2. Schematic of the five anticodon loop circuits discussed in this review. (A) $\mathrm{Cm}_{32}$ and $\mathrm{Gm}_{34}$ drive $\mathrm{yW}_{37}$ formation in tRNA ${ }^{\text {Phe }}$ of $S$. pombe, $S$. cerevisiae, and humans. (B) $i^{6} A_{37}$ drives $\mathrm{m}^{3} \mathrm{C}_{32}$ formation in tRNA ${ }^{\text {Ser }}$ of $S$. pombe and $S$. cerevisiae, and $\mathrm{t}^{6} \mathrm{~A}_{37}$ drives $\mathrm{m}^{3} \mathrm{C}_{32}$ formation in tRNA ${ }^{\text {Thr }}$ of $S$. cerevisiae. (C) $i^{6} A_{37}$ drives $\mathrm{Cm}_{34}$ and $\mathrm{Um}_{34}$ formation in TRNA ${ }^{\text {Leu(CAA) }}$ and tRNA ${ }^{\text {Leu(UAA) }}$ of E. coli. (D) $\mathrm{Q}_{34}$ drives $m^{5} \mathrm{C}_{38}$ formation in $\mathrm{tRNA} \mathrm{Asp}^{\mathrm{Asp}}$ of $S$. pombe and D. discoideum. (E) $\mathrm{C}_{32}$ to $\mathrm{m}^{3} \mathrm{C}_{32}$ to $\mathrm{m}^{3} \mathrm{U}_{32}$ drives $\mathrm{I}_{34}$ formation in $\mathrm{RNA} \mathrm{A}^{\text {Thr(AGU) }}$ of $T$. brucei. 




FIGURE 3. Schematic of the S. cerevisiae ACL landscape.

in this region, combined with the lack of variability in the local sequence and structure. Indeed, the ACL sequence outside the anticodon itself has limited variation: $\mathrm{N}_{33}$ is almost always a uridine in elongator tRNAs; $N_{37}$ is almost always a purine; and the vast majority of $\mathrm{N}_{32}-\mathrm{N}_{38}$ combinations are C-A, U-A, or U-U (Auffinger and Westhof 1999; Marck and Grosjean 2002). Of the 2726 tDNA gene sequences in the tRNA database, $48 \%$ of $\mathrm{N}_{32}-\mathrm{N}_{38}$ pairs are C-A, $18 \%$ are U-A, and $11 \%$ are U-U (Auffinger and Westhof 1999; Marck and Grosjean 2002); while in yeast $52 \%$ of $\mathrm{N}_{32}-\mathrm{N}_{38}$ pairs are C-A, 19\% are U-A, and 19\% are U-C (Fig. 3; Jühling et al. 2009). Thus, the majority of sequence variation in the $A C L$ region comes from the anticodon sequence, which is a unique signature for each tRNA species and is often important for tRNA synthetase recognition (Kisselev 1985; Giegé et al. 1998). Moreover, as addressed above, the universal conservation of anticodon stem-loop structure is selected by the translation machinery, so structural information in this region is unlikely to be useful for individual enzyme specificity. The conserved sequence and structural similarities in the $A C L$ region provide little room for substrate recognition of $A C L$ modifying enzymes, if their specificities solely come from sequence elements around the modification site. Therefore, it is reasonable to speculate that evolution may have selected for modification circuits in which modifications introduced first positively or negatively regulate formation of other nearby modifications, adding another layer of complexity in the $A C L$ region to enhance enzyme modification specificity.

Three mechanisms might explain the observed ordered modification circuits in ACLs (Fig. 4). First, the initial modification might directly act as a recognition element for the subse- quent modification enzyme, much like bromodomains found in chromatin-associated proteins and nuclear acetyltransferases, which bind acetyl-lysine (Zeng and Zhou 2002). A classical example of this mechanism of ordered modification is queuosine formation at residue 34 in marsupial mitochondrial tRNA ${ }^{\text {Asp }}$. This modification requires prior deamination of $\mathrm{C}_{35}$ of the encoded $\mathrm{GCC}$ anticodon to form a GUC anticodon, generating the $\mathrm{U}_{33} \mathrm{G}_{34} \mathrm{U}_{35}$ recognition sequence for tRNA guanine transglycosylase to catalyze queuosine formation (Morl et al. 1995; Börner et al. 1996; Xie et al. 2003). Second, the initial modification might alter the structure of the ACL to present a structure that is itself recognized or properly exposes the target residue for the subsequent modification enzyme. Third, an initial modification might prevent a particular subsequent modification from occurring, allowing a different modification enzyme to act in its stead. Although the precise mechanism by which any of the recently established ordered modification circuits is not yet known, we describe below what is known in each case.

The $\mathrm{yW}_{37}$ modification, or derivatives of it, is almost universally found on tRNA ${ }^{\text {Phe }}$ in eukaryotes, and not on any other tRNA (Machnicka et al. 2013), and it is known

\section{A}
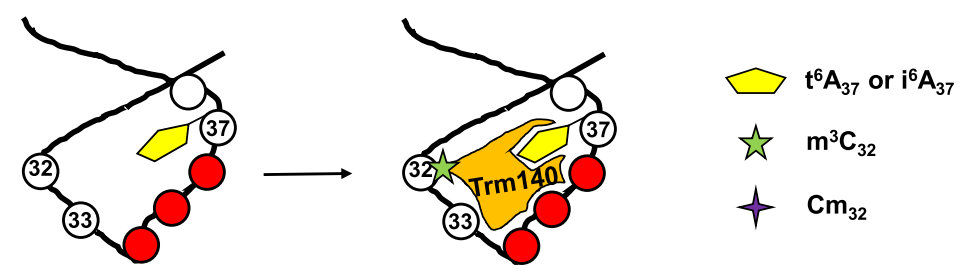

B

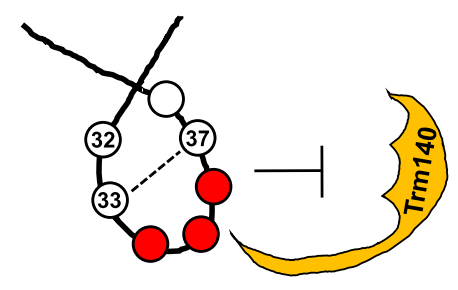

disordered $\mathrm{ACL}$ region

/buried residue
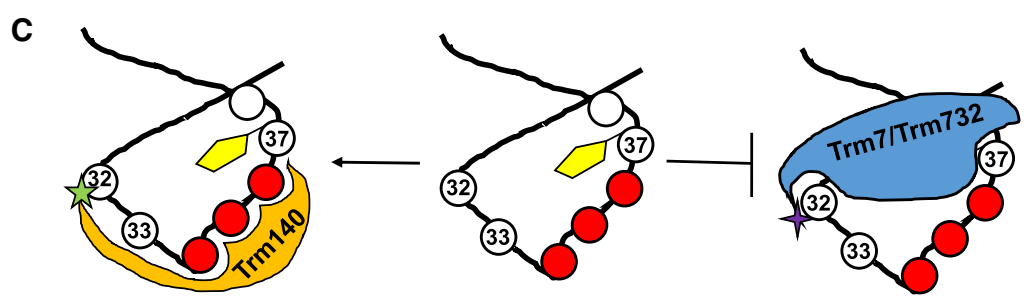

FIGURE 4. Three possible mechanisms to explain the ordered modification circuits in the ACL region, using the $i^{6} A_{37} / t^{6} A_{37}-m^{3} C_{32}$ circuit as an example. (A) The initial modification $\left(i^{6} A_{37}\right.$ or $t^{6} A_{37}$ ) directly acts as a recognition element for the subsequent modification enzyme (Trm140 for $\mathrm{m}^{3} \mathrm{C}_{32}$ modification). (B) The initial modification ( $i^{6} \mathrm{~A}_{37}$ or $\mathrm{t}^{6} \mathrm{~A}_{37}$ ) alters the structure of the $A C L$ to present a structure that is itself recognized or properly exposes the target residue $\left(C_{32}\right)$ for the subsequent modification enzyme (Trm140). (C) The initial modification $\left({ }^{6} A_{37}\right.$ or $\left.t^{6} A_{37}\right)$ prevents a subsequent modification from occurring $\left(\mathrm{Cm}_{32}\right.$ by $\left.T r m 7 / 732\right)$, allowing a different modification enzyme (Trm140) to act instead. 
that the GAA anticodon sequence is necessary for $\mathrm{yW}$ formation in oocytes (Droogmans and Grosjean 1987). $\mathrm{yW}$ formation is the last step of tRNA ${ }^{\text {Phe }}$ maturation, and the critical 2'-O-methylation of $\mathrm{C}_{32}$ and $\mathrm{N}_{34}$ required for efficient $\mathrm{yW}$ formation (Guy et al. 2012) is part of an intricate RRNA $^{\text {Phe }}$ maturation pathway in $S$. cerevisiae (Ohira and Suzuki 2011). These steps include initial export of unspliced pre-tRNA from the nucleus to the cytoplasm (Sarkar and Hopper 1998), tRNA splicing on the mitochondrial surface (Yoshihisa et al. 2007), 2'-O-methylation of $\mathrm{C}_{32}$ and $\mathrm{N}_{34}$ by Trm7/Trm732 and Trm7/Trm734 (Guy et al. 2012), retrograde transport of the tRNA back to the nucleus (Takano et al. 2005; Murthi et al. 2010), formation of $\mathrm{m}^{1} \mathrm{G}_{37}$, reexport of the tRNA ${ }^{\text {Phe }}$ to the cytoplasm, and then further modification of $\mathrm{m}^{1} \mathrm{G}_{37}$ by Tyw1, Tyw2, Tyw3, and Tyw4 to form yW (Noma et al. 2006; Ohira and Suzuki 2011). There is an apo structure of Tyw1, which catalyzes the first step of $y W$ from $\mathrm{m}^{1} \mathrm{G}_{37}$, from Methanococcus jannaschii and Pyrococcus horikoshii (Goto-lto et al. 2007; Suzuki et al. 2007); however, little insight is provided for the specificity of the enzyme.

The dependence of $\mathrm{yW}_{37}$ formation on prior $\mathrm{Cm}_{32}$ and $\mathrm{Gm}_{34}$ modification in S. cerevisiae, S. pombe, and humans (Guy and Phizicky 2015; Guy et al. 2012, 2015) could be explained by one of the first two mechanisms mentioned above: direct Tyw1 recognition of $\mathrm{Cm}_{32}$ and $\mathrm{Gm}_{34}$; and Tyw1 recognition of the prestructured $A C L$ region possibly including increased Tyw 1 access to $\mathrm{m}^{1} \mathrm{G}_{37}$. Both models would be consistent with the partial modification of $\mathrm{yW}$ observed in trm7344 mutants, which have the $\mathrm{Cm}_{32}$ modification but not $\mathrm{Gm}_{34}$ and trm732 4 mutants, which have $\mathrm{Gm}_{34}$, but not $\mathrm{Cm}_{32}$ (Guy and Phizicky 2015; Guy et al. 2012, 2015).

The $\mathrm{m}^{3} \mathrm{C}_{32}$ modification is found in almost all sequenced tRNA $^{\text {Ser }}$ and tRNA $^{\text {Thr }}$ species with $C_{32}$, as well as in mammalian tRNA ${ }^{\mathrm{Arg}(\mathrm{CCU})}$ and tRNA ${ }^{\mathrm{Arg}(\mathrm{UCU})}$, but not in other tRNA species. In S. cerevisiae, a single Trm 140 homolog catalyzes $\mathrm{m}^{3} \mathrm{C}_{32}$ formation in all six of its tRNA ${ }^{\mathrm{Thr}}$ and tRNA ${ }^{\text {Ser }}$ substrates (D'Silva et al. 2011; Noma et al. 2011), whereas in $S$. pombe there are two paralogs, one responsible for tRNA $^{\text {Ser }}$ modification and the other for tRNA $^{\text {Thr }}$ modification (Arimbasseri et al. 2016). S. cerevisiae Trm140 has two recognition modes for its substrates, and each involves $\mathrm{t}^{6} \mathrm{~A}$ and/or $\mathrm{i}^{6} \mathrm{~A}$ : $\operatorname{Trm} 140$ recognizes the sequence element $\mathrm{G}_{35}-\mathrm{U}_{36}-\mathrm{t}^{6} \mathrm{~A}_{37}$ of tRNA ${ }^{\text {Thr }}$ substrates, and this sequence element is necessary and sufficient for $\mathrm{m}^{3} \mathrm{C}$ modification of another tRNA species (Han et al. 2017). In contrast, Trm140 recognizes tRNA ${ }^{\text {Ser }}$ species through interaction with seryl-tRNA synthetase and the distinctive tRNA $^{\text {Ser }}$ variable loop recognized by SerRS (Himeno et al. 1997), as well as by either $t^{6} A_{37}$ or $i^{6} A_{37}$ (Han et al. 2017). In both sets of substrates, $A_{37}$ modifications (either $i^{6} \mathrm{~A}$ or $\mathrm{t}^{6} \mathrm{~A}$ ) are stimulatory, but not absolutely necessary for $\mathrm{m}^{3} \mathrm{C}_{32}$ formation, and available data suggests that each element of tRNA ${ }^{\text {Thr }}$ and tRNA ${ }^{\text {Ser }}$ recognition contributes independently to $\operatorname{Trm} 140$ recognition, including $t^{6} \mathrm{~A}$ and $i^{6} \mathrm{~A}$ (Han et al. 2017). A similar result was previously observed in $S$. pombe in which $i^{6} A_{37}$ stimulates $\mathrm{m}^{3} \mathrm{C}_{32}$ formation for all three tRNA ${ }^{\text {Ser }}$ species with the modification (Arimbasseri et al. 2016).

The role of $\mathrm{t}^{6} \mathrm{~A}_{37}$ or $\mathrm{i}^{6} \mathrm{~A}_{37}$ in stimulating $\mathrm{m}^{3} \mathrm{C}_{32}$ modification by Trm 140 family members is unclear, but it seems unlikely that $S$. cerevisiae Trm140 directly recognizes both modifications, since they are chemically very distinct: The isopentenyl group of $i^{6} \mathrm{~A}$ is much more hydrophobic than the acidic and polar threonyl group found in $\mathrm{t}^{6} \mathrm{~A}$. A more plausible explanation is that both $i^{6} \mathrm{~A}$ and $t^{6} \mathrm{~A}$ facilitate formation of the proper structure of the tRNA $A C L$, allowing for Trm140 recognition and $\mathrm{m}^{3} \mathrm{C}_{32}$ modification. Indeed, $t^{6} A_{37}$ has been shown to have a role in preordering the ACL by preventing base-pairing between $U_{33}$ and $A_{37}$, and by enhancing stacking interactions between $A_{37}$ and $A_{38}$ (Murphy et al. 2004). It is also possible that the bulky $t^{6} \mathrm{~A}$ and $i^{6} \mathrm{~A}$ modifications act as a negative recognition element for $\mathrm{Trm} 7 / \mathrm{Trm} 732$, to prevent $\mathrm{Cm}_{32}$ modification in S. cerevisiae (Guy et al. 2012), although its recognition elements are not yet known.

Similarly, any of the three mechanisms might also be used to explain the dependence of $\mathrm{Cm}_{34}$ and $\mathrm{Um}_{34}$ on prior $i^{6} A_{37}$ modification in E.coli. The E. coli $\mathrm{N}_{34} 2^{\prime}-\mathrm{O}$ methytransferase $\mathrm{TrmL}$ catalyzes this methyl transfer reaction on its two substrates, tRNA ${ }^{\text {Leu(CAA) }}$ and tRNA ${ }^{\text {Leu(UAA) }}$ (Liu et al. 2013). The presence of $i^{6} A_{37}$, which is catalyzed by MiaA (Soderberg and Poulter 2001), strongly stimulates formation of $\mathrm{Cm}_{34}$ and $\mathrm{Um}_{34}$, since in vitro transcribed tRNA ${ }^{\text {Leu(CAA) }}$ and tRNA ${ }^{\text {Leu(UAA) }}$ without modifications are not substrates of TrmL, while the same tRNA transcripts are efficient $T r m L$ substrates if they are premodified by recombinant MiaA (Zhou et al. 2015). In the same study, the sequence $A_{36}-A_{37}-A_{38}$ was shown to be important for $\mathrm{Cm}_{34}$ and $\mathrm{Um}_{34}$ formation; however, whether this sequence element is necessary for recognition by $\operatorname{TrmL}$ itself or for the $i^{6} A_{37}$ modification is unclear, since the $A_{36}-A_{37}$ $A_{38}$ motif is the known determinant for MiaA (Soderberg and Poulter 2001).

For $\mathrm{m}^{5} \mathrm{C}_{38}$ modification of tRNA ${ }^{\text {Asp }}$ in $S$. pombe, the stimulatory role of $\mathrm{O}_{34}$ has been demonstrated both in vivo and in vitro with purified Pmt1 methyltransferase (Muller et al. 2015). This experiment suggests either that Pmt1 directly interacts with $\mathrm{Q}_{34}$, or that $\mathrm{Q}_{34}$ appropriately affects the ACL structure of tRNA ${ }^{\text {Asp }}$. The crystal structures of several Dnmt2 homologs have been solved, but unfortunately without the tRNA substrate (Dong et al. 2001; Schulz et al. 2012; Li et al. 2013). Based on a modeled tRNA ${ }^{\text {Asp }}$-Dnmt2 structure, it is also possible that $\mathrm{Q}_{34}$ could alter the geometry of the $A C L$, allowing for better interactions between Dnmt2 and tRNA. Nonetheless, $\mathrm{Q}_{34}$ cannot be the sole determinant, since the tRNA guanine transglycosylase (TGT) that exchanges $G$ with $Q$ in tRNAs acts on 
all tRNAs with a GUN anticodon (Katze et al. 1982), whereas $\mathrm{m}^{5} \mathrm{C}_{38}$ is specific for tRNA Asp.

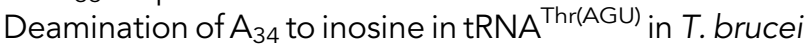
is stimulated by $C_{32}$ deamination to uridine, based on the observation that in vitro transcribed tRNA ${ }^{\operatorname{Thr}(A G U)}$ with $U_{32}$ is edited to $I_{34}$ with higher efficiency and initial rate than transcripts with $\mathrm{C}_{32}$ (Rubio et al. 2006). Remarkably, recent results show that the initial $\mathrm{C}$ to $\mathrm{U}$ editing step is preceded by $\mathrm{m}^{3} \mathrm{C}$ modification by a complex of the $\mathrm{m}^{3} \mathrm{C}$ methyltransferase Trm140 and the deaminase ADAT2/3, which catalyzes both reactions (Rubio et al. 2017; McKenney et al. 2018). While formation of $\mathrm{m}^{3} \mathrm{C}_{32}$ followed by formation of $\mathrm{m}^{3} \mathrm{U}_{32}$ occurs in the nucleus prior to $5^{\prime}$ leader removal and export of tRNA into cytoplasm, A to I editing at the wobble residue occurs in the cytoplasm (Gaston et al. 2007). As in the other cases, it is unclear how $\mathrm{m}^{3} U_{32}$ stimulates the subsequent $A_{34}$ deamination.

In summary, we have documented a large number of modifications in the $A C L$ region that depend on prior modifications in the tRNA, and have proposed that the modification circuits may have evolved so that the second modification in the circuit can use additional recognition sites directly or indirectly from the first modification to achieve specificity. This helps resolve the dilemma in the $A C L$ region of the need for different modifications at the same residue, combined with the lack of sufficient sequence variation or structural information to obtain the desired specificity. In principle, the anticodon sequence or set of anticodon sequences can provide some of the required specificity, but not always, such as in the case of $\mathrm{m}^{3} \mathrm{C}$ modification, which acts on tRNAs with very different anticodons. In all of these documented cases, lack of the first modifications in nonsubstrate tRNAs would also prevent the second modifications in these tRNAs, thereby improving overall specificity of modifications in the entire tRNA population. This set of five modification circuits within the $A C L$, and the phylogenetic conservation of two of them, suggest the existence of other modification circuits in the ACLs of different tRNA species or organisms, driven in part by the need for specific substrate recognition.

\section{ACKNOWLEDGMENTS}

We thank Elizabeth Grayhack for valuable comments on the manuscript. This work was supported by National Institute of General Medical Sciences, National Institutes of Health grant GM052347 to E.M.P.

\section{REFERENCES}

Agris PF. 2008. Bringing order to translation: the contributions of transfer RNA anticodon-domain modifications. EMBO Rep 9: 629-635.

Arimbasseri AG, Iben J, Wei FY, Rijal K, Tomizawa K, Hafner M, Maraia RJ. 2016. Evolving specificity of tRNA 3-methyl-cytidine- $32\left(\mathrm{~m}^{3} \mathrm{C}_{32}\right)$ modification: a subset of tRNAs ${ }^{\text {Ser }}$ requires $N^{6}$-isopentenylation of $A_{37}$. RNA 22: 1400-1410.

Auffinger P, Westhof E. 1999. Singly and bifurcated hydrogenbonded base-pairs in tRNA anticodon hairpins and ribozymes. J Mol Biol 292: 467-483.

Auffinger $P$, Westhof E. 2001. An extended structural signature for the tRNA anticodon loop. RNA 7: 334-341.

Becker HF, Motorin Y, Sissler M, Florentz C, Grosjean H. 1997. Major identity determinants for enzymatic formation of ribothymidine and pseudouridine in the TY-loop of yeast tRNAs. J Mol Biol 274: 505-518.

Björk GR, Wikström PM, Byström AS. 1989. Prevention of translational frameshifting by the modified nucleoside 1-methylguanosine. Science 244: 986-989.

Björk GR, Huang B, Persson OP, Byström AS. 2007. A conserved modified wobble nucleoside $\left(\mathrm{mcm}^{5} \mathrm{~s}^{2} \mathrm{U}\right)$ in lysyl-tRNA is required for viability in yeast. RNA 13: 1245-1255.

Börner GV, Mörl M, Janke A, Pääbo S. 1996. RNA editing changes the identity of a mitochondrial tRNA in marsupials. EMBO J 15: 5949-5957.

Byrne RT, Jenkins HT, Peters DT, Whelan F, Stowell J, Aziz N, Kasatsky P, Rodnina MV, Koonin EV, Konevega AL, et al. 2015. Major reorientation of tRNA substrates defines specificity of dihydrouridine synthases. Proc Natl Acad Sci 112: 6033-6037.

Cavaillé J, Chetouani F, Bachellerie JP. 1999. The yeast Saccharomyces cerevisiae YDL112w ORF encodes the putative 2'-O-ribose methyltransferase catalyzing the formation of Gm18 in tRNAs. RNA 5: 66-81.

de Crécy-Lagard V, Marck C, Grosjean H. 2012. Decoding in Candidatus Riesia pediculicola, close to a minimal tRNA modification set? Trends Cell Mol Biol 7: 11-34.

Deutsch C, El Yacoubi B, de Crécy-Lagard V, Iwata-Reuyl D. 2012. Biosynthesis of threonylcarbamoyl adenosine $\left(t^{6} \mathrm{~A}\right)$, a universal tRNA nucleoside. J Biol Chem 287: 13666-13673.

Dong A, Yoder JA, Zhang X, Zhou L, Bestor TH, Cheng X. 2001. Structure of human DNMT2, an enigmatic DNA methyltransferase homolog that displays denaturant-resistant binding to DNA. Nucleic Acids Res 29: 439-448.

Droogmans L, Grosjean H. 1987. Enzymatic conversion of guanosine $3^{\prime}$ adjacent to the anticodon of yeast tRNA ${ }^{\text {Phe }}$ to $N^{1}$-methylguanosine and the wye nucleoside: dependence on the anticodon sequence. EMBO J 6: 477-483.

D'Silva S, Haider SJ, Phizicky EM. 2011. A domain of the actin binding protein Abp140 is the yeast methyltransferase responsible for 3-methylcytidine modification in the tRNA anti-codon loop. RNA 17: 1100-1110.

El Yacoubi B, Hatin I, Deutsch C, Kahveci T, Rousset JP, Iwata-Reuyl D, Murzin AG, de Crécy-Lagard V. 2011. A role for the universal Kae1/ Qri7/YgjD (COG0533) family in tRNA modification. EMBO J 30: 882-893.

Gaston KW, Rubio MA, Spears JL, Pastar I, Papavasiliou FN, Alfonzo JD. 2007. C to $U$ editing at position 32 of the anticodon loop precedes tRNA $5^{\prime}$ leader removal in trypanosomatids. Nucleic Acids Res 35: 6740-6749.

Gerber AP, Keller W. 1999. An adenosine deaminase that generates inosine at the wobble position of tRNAs. Science 286: 1146-1149.

Giegé R, Sissler M, Florentz C. 1998. Universal rules and idiosyncratic features in tRNA identity. Nucleic Acids Res 26: 5017-5035.

Goto-Ito S, Ishii R, Ito T, Shibata R, Fusatomi E, Sekine SI, Bessho Y, Yokoyama S. 2007. Structure of an archaeal TYW1, the enzyme catalyzing the second step of wye-base biosynthesis. Acta Crystallogr D Biol Crystallogr 63: 1059-1068.

Grosjean H, Westhof E. 2016. An integrated, structure- and energybased view of the genetic code. Nucleic Acids Res 44: 8020-8040. 
Grosjean H, Constantinesco F, Foiret D, Benachenhou N. 1995 A novel enzymatic pathway leading to 1-methylinosine modification in Haloferax volcanii tRNA. Nucleic Acids Res 23: 4312-4319.

Gu C, Begley TJ, Dedon PC. 2014. tRNA modifications regulate translation during cellular stress. FEBS Lett 588: 4287-4296.

Guy MP, Phizicky EM. 2015. Conservation of an intricate circuit for crucial modifications of the tRNA ${ }^{\text {Phe }}$ anticodon loop in eukaryotes. RNA 21: 61-74.

Guy MP, Podyma BM, Preston MA, Shaheen HH, Krivos KL, Limbach PA, Hopper AK, Phizicky EM. 2012. Yeast Trm7 interacts with distinct proteins for critical modifications of the tRNA ${ }^{\text {Phe }}$ anticodon loop. RNA 18: 1921-1933.

Guy MP, Shaw M, Weiner CL, Hobson L, Stark Z, Rose K, Kalscheuer VM, Gecz J, Phizicky EM. 2015. Defects in tRNA anticodon loop 2'-O-methylation are implicated in nonsyndromic X-linked intellectual disability due to mutations in FTSJ1. Hum Mutat 36: 1176-1187.

Han L, Kon Y, Phizicky EM. 2015. Functional importance of $\Psi^{38}$ and $\Psi^{39}$ in distinct tRNAs, amplified for tRNA ${ }^{\text {Gln(UUG) }}$ by unexpected temperature sensitivity of the $s^{2} U$ modification in yeast. RNA 21: 188-201.

Han L, Marcus E, D'Silva S, Phizicky EM. 2017. S. cerevisiae Trm140 has two recognition modes for 3-methylcytidine modification of the anticodon loop of tRNA substrates. RNA 23: 406-419.

Himeno H, Yoshida S, Soma A, Nishikawa K. 1997. Only one nucleotide insertion to the long variable arm confers an efficient serine acceptor activity upon Saccharomyces cerevisiae tRNA ${ }^{\text {Leu }}$ in vitro. J Mol Biol 268: 704-711.

Huang B, Johansson MJ, Byström AS. 2005. An early step in wobble uridine tRNA modification requires the Elongator complex. RNA 11: 424-436.

Hur S, Stroud RM. 2007. How U38, 39, and 40 of many tRNAs become the targets for pseudouridylation by TruA. Mol Cell 26: 189-203.

Ishida K, Kunibayashi T, Tomikawa C, Ochi A, Kanai T, Hirata A, Iwashita C, Hori H. 2011. Pseudouridine at position 55 in tRNA controls the contents of other modified nucleotides for low-temperature adaptation in the extreme-thermophilic eubacterium Thermus thermophilus. Nucleic Acids Res 39: 2304-2318.

Ishitani R, Nureki O, Nameki N, Okada N, Nishimura S, Yokoyama S. 2003. Alternative tertiary structure of tRNA for recognition by a posttranscriptional modification enzyme. Cell 113: 383-394.

Jiang HQ, Motorin Y, Jin YX, Grosjean H. 1997. Pleiotropic effects of intron removal on base modification pattern of yeast $t R N A^{\text {Phe }}$ : an in vitro study. Nucleic Acids Res 25: 2694-2701.

Johansson MJ, Esberg A, Huang B, Björk GR, Byström AS. 2008. Eukaryotic wobble uridine modifications promote a functionally redundant decoding system. Mol Cell Biol 28: 3301-3312.

Jühling F, Mörl M, Hartmann RK, Sprinzl M, Stadler PF, Pütz J. 2009. tRNAdb 2009: compilation of tRNA sequences and tRNA genes. Nucleic Acids Res 37: D159-162.

Katze JR, Basile B, McCloskey JA. 1982. Queuine, a modified base incorporated posttranscriptionally into eukaryotic transfer RNA: wide distribution in nature. Science 216: 55-56.

Kisselev LL. 1985. The role of the anticodon in recognition of tRNA by aminoacyl-tRNA synthetases. Prog Nucleic Acid Res Mol Biol 32: 237-266.

Kotelawala L, Grayhack EJ, Phizicky EM. 2008. Identification of yeast tRNA Um44 2'-O-methyltransferase (Trm44) and demonstration of a Trm44 role in sustaining levels of specific tRNA ${ }^{\text {Ser }}$ species. RNA 14: 158-169.

Lecointe F, Namy O, Hatin I, Simos G, Rousset JP, Grosjean H. 2002. Lack of pseudouridine 38/39 in the anticodon arm of yeast cytoplasmic tRNA decreases in vivo recoding efficiency. J Biol Chem 277: 30445-30453.
Leulliot N, Chaillet M, Durand D, Ulryck N, Blondeau K, van Tilbeurgh H. 2008. Structure of the yeast tRNA m7G methylation complex. Structure 16: 52-61.

Li S, Du J, Yang H, Yin J, Ding J, Zhong J. 2013. Functional and structural characterization of DNMT2 from Spodoptera frugiperda. $J$ Mol Cell Biol 5: 64-66.

Liu RJ, Zhou M, Fang ZP, Wang M, Zhou XL, Wang ED. 2013. The tRNA recognition mechanism of the minimalist SPOUT methyltransferase, TrmL. Nucleic Acids Res 41: 7828-7842.

Lorenz C, Lünse CE, Mörl M. 2017. tRNA modifications: impact on structure and thermal adaptation. Biomolecules 7: E35.

Lovejoy AF, Riordan DP, Brown PO. 2014. Transcriptome-wide mapping of pseudouridines: pseudouridine synthases modify specific mRNAs in S. cerevisiae. PLoS One 9: e110799.

Machnicka MA, Milanowska K, Osman Oglou O, Purta E, Kurkowska M, Olchowik A, Januszewski W, Kalinowski S, DuninHorkawicz S, Rother KM, et al. 2013. MODOMICS: a database of RNA modification pathways-2013 update. Nucleic Acids Res 41: D262-D267.

Machnicka MA, Olchowik A, Grosjean H, Bujnicki JM. 2014. Distribution and frequencies of post-transcriptional modifications in tRNAs. RNA Biol 11: 1619-1629.

Maehigashi T, Dunkle JA, Miles SJ, Dunham CM. 2014. Structural insights into +1 frameshifting promoted by expanded or modification-deficient anticodon stem loops. Proc Natl Acad Sci 111: 12740-12745.

Marck C, Grosjean H. 2002. tRNomics: analysis of tRNA genes from 50 genomes of Eukarya, Archaea, and Bacteria reveals anticodon-sparing strategies and domain-specific features. RNA 8: 1189-1232.

McKenney KM, Rubio MAT, Alfonzo JD. 2018. Binding synergy as an essential step for tRNA editing and modification enzyme codependence in Trypanosoma brucei. RNA 24: 56-66.

Miyauchi K, Kimura S, Suzuki T. 2013. A cyclic form of $N^{6}$-threonylcarbamoyladenosine as a widely distributed tRNA hypermodification. Nat Chem Biol 9: 105-111.

Morl M, Dorner M, Paabo S. 1995. C to $U$ editing and modifications during the maturation of the mitochondrial tRNA ${ }^{\text {Asp }}$ in marsupials. Nucleic Acids Res 23: 3380-3384.

Motorin Y, Bec G, Tewari R, Grosjean H. 1997. Transfer RNA recognition by the Escherichia coli isopentenyl-pyrophosphate:tRNA-isopentenyl transferase: dependence on the anticodon arm structure. RNA 3: 721-733.

Muller M, Hartmann M, Schuster I, Bender S, Thuring KL, Helm M, Katze JR, Nellen W, Lyko F, Ehrenhofer-Murray AE. 2015. Dynamic modulation of Dnmt2-dependent tRNA methylation by the micronutrient queuine. Nucleic Acids Res 43: 10952-10962.

Muramatsu T, Nishikawa K, Nemoto F, Kuchino Y, Nishimura S, Miyazawa T, Yokoyama S. 1988. Codon and amino-acid specificities of a transfer RNA are both converted by a single post-transcriptional modification. Nature 336: 179-181.

Murphy FV IV, Ramakrishnan V. 2004. Structure of a purine-purine wobble base pair in the decoding center of the ribosome. Nat Struct Mol Biol 11: 1251-1252.

Murphy FV IV, Ramakrishnan V, Malkiewicz A, Agris PF. 2004. The role of modifications in codon discrimination by tRNA ${ }^{\text {Lys }}$ UuU. Nat Struct Mol Biol 11: 1186-1191.

Murthi A, Shaheen HH, Huang HY, Preston MA, Lai TP, Phizicky EM, Hopper AK. 2010. Regulation of tRNA bidirectional nuclear-cytoplasmic trafficking in Saccharomyces cerevisiae. Mol Biol Cell 21: 639-649.

Nishikura K, De Robertis EM. 1981. RNA processing in microinjected Xenopus oocytes. Sequential addition of base modifications in the spliced transfer RNA. J Mol Biol 145: 405-420. 
Noma A, Kirino Y, Ikeuchi Y, Suzuki T. 2006. Biosynthesis of wybutosine, a hyper-modified nucleoside in eukaryotic phenylalanine tRNA. EMBO J 25: 2142-2154.

Noma A, Yi S, Katoh T, Takai Y, Suzuki T, Suzuki T. 2011. Actin-binding protein ABP140 is a methyltransferase for 3-methylcytidine at position 32 of tRNAs in Saccharomyces cerevisiae. RNA 17: 1111-1119.

Ohira T, Suzuki T. 2011. Retrograde nuclear import of tRNA precursors is required for modified base biogenesis in yeast. Proc Natl Acad Sci 108: 10502-10507.

Okamoto H, Watanabe K, Ikeuchi $Y$, Suzuki T, Endo $Y$, Hori $H$. 2004. Substrate tRNA recognition mechanism of tRNA $\left(m^{7} G_{46}\right)$ methyltransferase from Aquifex aeolicus. J Biol Chem 279: 49151-49159.

Persson BC, Esberg B, Olafsson O, Björk GR. 1994. Synthesis and function of isopentenyl adenosine derivatives in tRNA. Biochimie 76: 1152-1160.

Phizicky EM, Hopper AK. 2010. tRNA biology charges to the front. Genes Dev 24: 1832-1860.

Pütz J, Florentz C, Benseler F, Giegé R. 1994. A single methyl group prevents the mischarging of a tRNA. Nat Struct Biol 1: 580-582.

Rubio MA, Ragone FL, Gaston KW, Ibba M, Alfonzo JD. 2006. C to U editing stimulates $A$ to I editing in the anticodon loop of a cytoplasmic threonyl tRNA in Trypanosoma brucei. J Biol Chem 281: 115-120.

Rubio MA, Gaston KW, McKenney KM, Fleming IM, Paris Z, Limbach PA, Alfonzo JD. 2017. Editing and methylation at a single site by functionally interdependent activities. Nature $\mathbf{5 4 2}$ 494-497.

Sarkar S, Hopper AK. 1998. tRNA nuclear export in Saccharomyces cerevisiae: in situ hybridization analysis. Mol Biol Cell 9: 3041-3055.

Schulz EC, Roth HM, Ankri S, Ficner R. 2012. Structure analysis of Entamoeba histolytica DNMT2 (EhMeth). PLoS One 7: e38728.

Shigi N, Suzuki T, Terada T, Shirouzu M, Yokoyama S, Watanabe K. 2006. Temperature-dependent biosynthesis of 2-thioribothymidine of Thermus thermophilus tRNA. J Biol Chem 281: 2104-2113.

Soderberg T, Poulter CD. 2001. Escherichia coli dimethylallyl diphosphate:tRNA dimethylallyltransferase: site-directed mutagenesis of highly conserved residues. Biochemistry 40: 1734-1740.
Suzuki Y, Noma A, Suzuki T, Senda M, Senda T, Ishitani R, Nureki O. 2007. Crystal structure of the radical SAM enzyme catalyzing tricyclic modified base formation in tRNA. J Mol Biol 372: 1204-1214.

Swinehart WE, Henderson JC, Jackman JE. 2013. Unexpected expansion of tRNA substrate recognition by the yeast $\mathrm{m} 1 \mathrm{G} 9$ methyltransferase Trm10. RNA 19: 1137-1146.

Takano A, Endo T, Yoshihisa T. 2005. tRNA actively shuttles between the nucleus and cytosol in yeast. Science 309: 140-142.

Tomikawa C, Yokogawa T, Kanai T, Hori H. 2010. $N^{7}$-methylguanine at position $46\left(\mathrm{~m}^{7} \mathrm{G}_{46}\right)$ in tRNA from Thermus thermophilus is required for cell viability at high temperatures through a tRNA modification network. Nucleic Acids Res 38: 942-957.

Urbonavicius J, Qian Q, Durand JM, Hagervall TG, Björk GR. 2001. Improvement of reading frame maintenance is a common function for several tRNA modifications. EMBO J 20: 4863-4873.

Waas WF, Druzina Z, Hanan M, Schimmel P. 2007. Role of a tRNA base modification and its precursors in frameshifting in eukaryotes. J Biol Chem 282: 26026-26034.

Weixlbaumer A, Murphy FV IV, Dziergowska A, Malkiewicz A, Vendeix FA, Agris PF, Ramakrishnan V. 2007. Mechanism for expanding the decoding capacity of transfer RNAs by modification of uridines. Nat Struct Mol Biol 14: 498-502.

Wilkinson ML, Crary SM, Jackman JE, Grayhack EJ, Phizicky EM. 2007. The 2'-O-methyltransferase responsible for modification of yeast tRNA at position 4. RNA 13: 404-413.

Xie W, Liu X, Huang RH. 2003. Chemical trapping and crystal structure of a catalytic tRNA guanine transglycosylase covalent intermediate. Nat Struct Biol 10: 781-788.

Yokoyama S, Watanabe K, Miyazawa T. 1987. Dynamic structures and functions of transfer ribonucleic acids from extreme thermophiles. Adv Biophys 23: 115-147.

Yoshihisa T, Ohshima C, Yunoki-Esaki K, Endo T. 2007. Cytoplasmic splicing of tRNA in Saccharomyces cerevisiae. Genes Cells 12: 285-297.

Zeng L, Zhou MM. 2002. Bromodomain: an acetyl-lysine binding domain. FEBS Lett 513: 124-128.

Zhou M, Long T, Fang ZP, Zhou XL, Liu RJ, Wang ED. 2015. Identification of determinants for tRNA substrate recognition by Escherichia coli $\mathrm{C} / \mathrm{U}_{34}$ 2'-O-methyltransferase. RNA Biol 12: 900-911. 

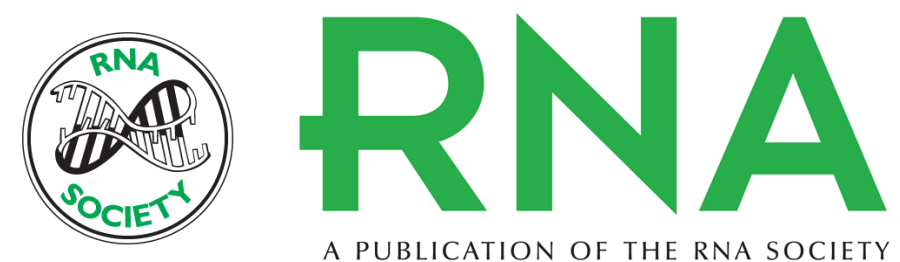

A PUBLICATION OF THE RNA SOCIETY

\section{A rationale for tRNA modification circuits in the anticodon loop}

Lu Han and Eric M. Phizicky

RNA 2018 24: 1277-1284 originally published online July 19, 2018

Access the most recent version at doi:10.1261/rna.067736.118

\section{References}

Creative

Commons

License

Email Alerting Service
This article cites 85 articles, 38 of which can be accessed free at: http://rnajournal.cshlp.org/content/24/10/1277.full.html\#ref-list-1

This article is distributed exclusively by the RNA Society for the first 12 months after the full-issue publication date (see http://rnajournal.cshlp.org/site/misc/terms.xhtml). After 12 months, it is available under a Creative Commons License (Attribution-NonCommercial 4.0 International), as described at http://creativecommons.org/licenses/by-nc/4.0/.

Receive free email alerts when new articles cite this article - sign up in the box at the top right corner of the article or click here. 